\section{(6) OPEN ACCESS}

${ }^{1}$ Department of Biomedical Ethics, School of Public Health, University of Tokyo Graduate School of Medicine, Tokyo, Japan

${ }^{2}$ Department of Bioethics and Humanities, University of Washington School of Medicine, Seattle, Washington, USA ${ }^{3}$ Department of Philosophy, University ofJohannesburg, Johannesburg, South Africa

Correspondence to Dr Akira Akabayashi, Department of Biomedical Ethics, School of Public Health, University of Tokyo Graduate School of Medicine, Tokyo 113 0033, Japan;

akirasan-tky@umin.ac.jp

Received 20 June 2018 Accepted 13 July 2018 Published Online First 7 August 2018

\title{
Endangerment of the iPSC stock project in Japan: on the ethics of public funding policies
}

\author{
Akira Akabayashi, ${ }^{1}$ Eisuke Nakazawa, ${ }^{1}$ Nancy S Jecker ${ }^{2,3}$
}

\begin{abstract}
We examined the ethical justification for a national policy governing public funding for the induced pluripotent stem cell (iPSC) stock project in Japan and argue that the initiation of the iPSC stock project in 2012, when no clinical trial using iPSC-derived products had yet succeeded, was premature and unethical. Our analysis considers a generally accepted justice criterion and shows it fails to justify public funding of the iPSC stock project. We also raise concerns related to the massive amounts of public funding at stake and the absence of evidence supporting claimed success rates. We conclude that the iPSC stock project should be re-considered and deferred until a substantial number of clinical trials using iPSC-derived products are deemed successful. This analysis should benefit others worldwide as they consider their own public funding policies.
\end{abstract}

\section{INTRODUCTION}

Over the last decade, the global scientific community has closely followed the progress of regenerative medicine, particularly stem cell research using induced pluripotent stem cells (iPSCs).

One reason for the popularity of iPSC lines is that they avoid the need to destroy human embryos, thus eliminating a major ethical obstacle to conducting such research. Another reason for the popularity of iPSC lines is that the Nobel Prize was awarded to a Japanese researcher for the discovery of iPSCs in 2012, generating optimism among the Japanese government, press, general public and researchers, all of whom believe that the country can and should pioneer the field of regenerative medicine through the national promotion of iPSC research.

Here, we analyse Japan's national public funding policy for the iPSC stock (bank) project from an ethical perspective. By sharing what we have learnt, we hope that our experiences may benefit other countries in their decision-making concerning public funding policies.

\section{BACKGROUND}

Publicly funded regenerative medicine research in Japan has created turmoil and controversy in recent years. Under particular scrutiny in this paper is the 'iPSC stock' project, the objective of which was to establish an allogeneic iPSC bank covering roughly $80 \%$ of Japan's population, primarily for treatment purposes. ${ }^{1}$ These iPSC stock cells are expected to yield lower rejection rates in transplantation, as the iPSC stock cells are established from the cells of individuals with HLA types known to cause fewer rejection reactions.
In 2012, the Japanese government decided to invest JPY110 billion (US\$ 1.1 billion) over 10 years in regenerative medicine research; a quarter of this was to be allocated to the iPSC stock project. ${ }^{2}$

However, on 13 December 2017, Dr Shinya Yamanaka (Director of CiRA, Center for iPS Cell Research and Application) reported that, to date, the iPSC stock project had established only two cell lines covering 24\% of the Japanese population. Dr Yamanaka indicated that CiRA aims to achieve 50\% coverage by the end of FY2020; in issuing this statement, Dr Yamanaka effectively lowered the coverage goal substantially, as the initial objective was to cover roughly $80 \%$ of the population. ${ }^{3}$ Below we address whether public funding of the iPSC stock project was ethically justified, given this revelation of a reduced $30 \%$ coverage rate.

\section{ETHICAL ANALYSIS}

\section{Was it sound to initiate public funding of the iPSC stock project in 2012?}

We begin our analysis by looking at the soundness of the research initiation. It is important to place the potential clinical benefits of iPSC-derived products in the context of likelihood of potential clinical benefits. In this regard, it is sobering to note that, as of June 2018, no clinical trial using iPSCs has been clinically successful. Only one clinical application study for neovascular age-related macular degeneration is ongoing, and even this remains at an early stage of safety verification. ${ }^{4}$

More recently, on 16 May 2018, the Japanese Health Ministry Task Force conditionally approved a plan by an Osaka University team led by Dr Yoshiki Sawa to conduct the world's first clinical trial using heart muscle cell sheets created from iPSCs to treat patients with serious heart failure. ${ }^{5}$ The research team plans to use allogeneic cells from CiRA's iPSC stock bank. However, the success of this heart study is by no means guaranteed. ${ }^{6}$

Even assuming that the iPSC stock project succeeds, this by no means guarantees societal benefit since clinical trials using iPSCs have not succeeded yet. In this case, the established stock will not be used to treat patients and thus might be considered pointless.

However, it might be argued that societal benefits should be understood more broadly, encompassing not only the direct clinical applications of research but also the benefit of substantial progress moving research further along a research trajectory that brings us closer to direct clinical benefit. We have in mind instances where research results in major progress, yet without taking the final step to realise clinical endpoints. Such research may satisfy the broader goal of social benefit. In support of this broader standard, 
it could be argued that a broader standard recognises the reality that the pathway from basic science to the endpoint of clinical treatments is not clearly marked and may be difficult to distinguish while research is still ongoing.

Yet in response, we note that the iPSC stock project does not meet the broader social requirement of moving research substantially closer to clinical applications. Thus, even applying a broad measure, the requirement of social benefit is not met.

The recent trend among research studies using iPSC-derived products is to not match HLA types. In fact, according to two recent surveys by the CiRA and Asahi Newspaper, between half and two-thirds of the projects have not matched HLA types. ${ }^{7}$ If the demand for HLA matching is decreased, then the value of the iPSC stock bank will drop as well.

In response to strong urging from Dr Yamanaka, the Japanese government decided at the end of 2017 to continue public funding of this project.

\section{Do justice standards justify investing large amounts of public funding in the IPSC stock project?}

From the standpoint of justice, it becomes exceedingly difficult to justify massive spending on the iPSC stock project. ${ }^{8}$ The most promising ethical justification for the iPSC stock project appeals to Rawls's difference principle, which requires that social and economic inequalities work to 'the greatest benefit for the least advantaged' members of society. ${ }^{9}$ The least advantaged group in a research context might be interpreted as those suffering from rare intractable diseases affecting few people. It is true that pharmaceutical company funding is unlikely if the study-even if successfultargets rare diseases affecting small numbers.

Will 'The Difference Principle', ever serve as ground for justifying the investment of large amounts of public funding for the iPSC stock project? In response to this question, we note, first, that as a general principle, public funding requires transparency. How would the funding government and funded researchers explain the possibility of obtaining funding for the iPSC stock project by means of other sources, such as venture pharmaceutical companies or private foundations? Although generally conditions that impact small numbers are disadvantaged with respect to funding, the popularity and surge of interest in iPSC research in Japan means that all studies conducting this kind of research are more attractive to funders. In light of this, it is unclear that the difference principle applies here.

Second, in the case of the iPSC stock project, which would cover only $30 \%-50 \%$ of the Japanese population, why are all Japanese people (taxpayers) expected to contribute to this project equally? Especially given that $50 \%-70 \%$ of the Japanese population would not be covered and would not benefit from the iPSC stock bank, a better alternative might be for users to cover costs, or a larger share of costs. Is requiring all to pay equally fundamentally unfair?

Third, the government did not hold any public Q \& A session about the iPSC stock project. Even publicity for policy decision-making, a necessary condition of procedural justice, was not granted.

Fourth, strong support of a particular project lessens a nation's capacity to address other intractable, serious illnesses such as cancer or cerebrovascular disease. This causes inequalities in healthcare access and leaves the issue of disease prioritisation unaddressed. It might, for example, be argued that Japan runs behind other countries in novel cancer cell therapy, which make a potentially larger contribution than iPSC technology. ${ }^{10}$

Fifth, new drug innovation for rare intractable diseases could be achieved through other, better means, such as the use of well-organised disease-specific iPSC banks by RIKEN. ${ }^{11}$ RIKEN provides
$>210$ human lines of disease-specific iPSCs as well as 58 healthy adult iPSC lines to academic researchers and private companies. This is a perfect example of something worthy of massive public funding.

The above analysis supports the conclusion that even the noblest of intentions to advocate for the best interests of patients and treatment purposes secure no ethical justification (based on either 'The Difference Principle') to invest large amounts of public funding in the iPSC stock project.

\section{CONCLUSIONS}

Public funding sources and funded researchers should exercise extreme caution when using public funds. If clinical trials are successful in the future, then the iPSC stock would be a valuable resource. Unfortunately, the current value is unclear because clinical application (transplantation) of iPSC products has yet to be successful. If clinical application succeeds in only a few cases, or if the iPSC stock only covers half of the population at best, then public funding for the iPSC stock project cannot be justified. Our analysis examined one highly regarded ethical standard, the difference principle and showed it failed to justify public funding for the iPSC stock project.

The iPSC stock project's research funding policy that bases the investment of massive amounts of public funding on an overblown success rate (due to wishful thinking that lacks empirical backing) simply cannot be ethically justified. We conclude that the iPSC stock project should be reconsidered and deferred until a substantial number of clinical trials using iPSC-derived products report success.

Correction notice This article has been corrected since it was published Online First. The words 'heterogeneous' and 'heterologous' were corrected to 'allogeneic'

Acknowledgements The authors thank Fumiko Kan, Masako Yokoyama and Asuka Naramoto of the University of Tokyo for their technical assistance.

Contributors AA: conceptualisation, writing original draft, writing review and editing. EN: conceptualisation, formal analysis, writing review and editing. NJ: conceptualisation, writing review and editing.

Funding The authors have not declared a specific grant for this research from any funding agency in the public, commercial or not-for-profit sectors.

Disclaimer AA is President of the Japan Association for Bioethics however this paper reflects the authors' personal academic analyses and opinions. It does not represent JAB's official position on this issue.

Competing interests $A A$ is President of the Japan Association for Bioethics. EN and NJ have no conflict of interests to declare.

Ethics approval The University of Tokyo Faculty of Medicine Ethics Committee Office judged that this study does not need committee's approval because it does not use human materials.

Provenance and peer review Not commissioned; internally peer reviewed.

Open access This is an open access article distributed in accordance with the Creative Commons Attribution Non Commercial (CC BY-NC 4.0) license, which permits others to distribute, remix, adapt, build upon this work non-commercially, and license their derivative works on different terms, provided the original work is properly cited, appropriate credit is given, any changes made indicated, and the use is non-commercial. See: http://creativecommons.org/licenses/by-nc/4.0/.

\section{REFERENCES}

1 CiRA (Center for iPS Cell Research and Application). iPS Cell Stock for Regenerative Medicine. 2018 www.cira.kyoto-u.ac.jp/e/research/stock.html (accessed 19 Jun 2018).

2 Regenerative Medicine: Weak presence of Japan. Dissatisfaction to skewed research funding: Nikkei Newspaper, 2017. (in Japanese). (accessed 19 Jun 2018).

3 Asahi Digital News Paper. IPS stock will cover $50 \%$ of Japanese population: the protocol has been approved. 2017. (in Japanese) https://www.asahi.com/articles/ ASKDF7SMGKDFUBQU01T.html (accessed 19 Jun 2018).

4 Mandai M, Watanabe A, Kurimoto Y, et al. Autologous induced stem-cell-derived retinal cells for macular degeneration. N Engl J Med 2017;376:1038-46. 


\section{Brief report}

5 Cyranoski D. Nature News. Reprogrammed stem cells approved to mend hearts. Japanese study is only the second application of induced pluripotent stem cells in people. Nature 2018;557:619-20.

6 Editorials N. Racing hearts. Japan must show that a promising therapy for damaged hearts works as claimed. Nature 2018;557:611-2.

7 Asahi Digital Newspaper. iPSC: Many researches which do not match HLA patterns. 2018 https://digital.asahi.com/articles/ASL667KNRL66UBQU00P.html?rm=506 (accessed 19 Jun 2018).
8 Kymlicka W. Contemporary political philosophy: an introduction. 2. Oxford: Oxford University Press, 2002.

9 Rawls J. A theory of justice. 266. Cambridge Mass: Harvard University Press, 1999.

10 Tang J, Hubbard-Lucey VM, Pearce L, et al. The global landscape of cancer cell therapy. Nat Rev Drug Discov 2018;17:465-6.

11 RIKEN. Human iPS cells. cell.brc.riken.jp/en/hps (accessed 19 Jun 2018). 